\title{
A case of acute hyperparathyroidism, with thyrotoxicosis and pancreatitis, presenting as hyperemesis gravidarum
}

\author{
M. A. O. Soyannwo \\ M.B., Lond., M.R.C.P.I. \\ Research Fellow, \\ Northern Ireland Hospitals Authority \\ M. BELL \\ F.R.C.S. \\ Consultant Surgeon
}

\author{
Mary G. McGeown \\ M.D., Ph.D., (Belf.), M.R.C.P. (Edin.) \\ Consultant Medical Urologist, Department of \\ Nephrology, Belfast City Hospital, \\ and Department of Medicine, Queen's \\ University, Belfast
}

\author{
T. G. MiLlikeN \\ M.D., F.R.C.P.I., M.R.C.P. \\ Consultant Physician
}

Primary hyperparathyroidism usually has an insidious onset, presenting when genito-urinary complications have developed, with stones, nephrocalcinosis, impairment of renal function, polyuria and polydipsia; with skeleto-muscular involvement manifested as bone pains, tumours, pathological fractures or loss of energy and generalized weakness; with gastro-intestinal symptoms such as loss of appetite, nausea, vomiting, dyspepsia or constipation. Rarely, however, acute symptoms may develop de novo or be superimposed on the hitherto more chronic disease.

The association of hyperparathyroidism and thyrotoxicosis has been recognized for many years, and the combination has presented as an acute emergency occasionally (Austoni, 1965). The presentation of the combination of acute hyperparathyroidism and thyrotoxicosis as hyperemesis gravidarum seems to be unique.

\section{Case report}

A 28-year-old primigravida attended the Obstetric Unit of the South Tyrone Hospital, with persistent vomiting for more than 7 weeks. She was then about 16 weeks pregnant. She was admited as an emergency. On the day of admission she had lost consciousness for about $2 \mathrm{~min}$, with symmetrical twitching of both arms and legs. She had recently lost about $21 \mathrm{lb}$ in weight. She complained that she had had frequent micturition at night for some time. She did not vomit on the day following admission, and had a 'fair' urinary output. The blood pressure was $120 / 70 \mathrm{mmHg}$. The urine contained protein, and the blood urea was $141 \mathrm{mg} / 100 \mathrm{ml}$; plasma electrolytes $(\mathrm{mEq} / 1)$ were: potassium $3 \cdot 6, \mathrm{CO}_{2}$ CP 31.6, sodium 135. The haemoglobin was $8.4 \mathrm{~g} /$ $100 \mathrm{ml}$.

There was a history that 2 years previously she had developed a rigor while at work, associated with a sore throat. The following morning the urine had been dark-coloured and she had called her general practitioner, who had found that the urine contained blood. The temperature was $99 \cdot 6^{\circ} \mathrm{F}$, and the blood pressure $140 / 80$. She recovered quickly but protein continued to be present in the urine. She was seen by T.G.M. on 4 February 1964, when she was without complaints, was back at her work and apparently perfectly well. The blood pressure was $125 / 70$. The urine was free from protein, the blood urea was $29 \mathrm{mg} / 100 \mathrm{ml}$ and the haemoglobin was $80 \%$.

Because of the azotaemia discovered in the Obstetric Unit, she was transferred to the care of T.G.M.

She was found to be anaemic and have a dry skin. There was a small nodule in the right lobe of the thyroid, and a tender, probably enlarged, right kidney. The blood urea was then $172 \mathrm{mg} /$ $100 \mathrm{ml}$. A chest film showed a tiny cystic area in the tenth left rib, and an abdominal film bilateral nephrocalcinosis. Estimation of the serum calcium and alkaline phosphatase were arranged. During this period, despite gross dehydration, the urinary output was from 933 to $1140 \mathrm{ml} / 24 \mathrm{hr}$.

Three days later, the blood urea had risen to $238 / 100 \mathrm{ml}$. The plasma potassium was then $3.0 \mathrm{mEq} / 1$. Although the value of the serum 
calcium was not then known, the diagnosis of acute hyperparathyroidism seemed likely, and it was arranged to transfer the patient to the Renal Unit, in the meantime treating her with intravenous fluids to correct the deficiencies of water, sodium and potassium.

The following day she was transferred to the Renal Unit in the Belfast City Hospital.

On admission she was too ill to give a history but her relatives said that she had complained of pain in the tops of the feet. They had noticed that over the past few years she drank quantities of mineral waters. There was no history of taking vitamin $D$, alkalis or excessive amounts of milk.

On examination she was very ill with sunken eyes and loose skin. There was marked muscle wasting and hypotonia and she was hardly able to talk. The conjunctivae were markedly suffused but band keratopathy was not present. Slit-lamp examination could not be done. There were no sarcoid nodules or lymphadenopathy. The temperature was $98^{\circ} \mathrm{F}$, the systolic blood pressure was 80 , the diastolic could not be recorded. The pulse was regular at $145 / \mathrm{min}$. The uterus was enlarged to correspond to a $4 \frac{1}{2}$ months' pregnancy and was contracting firmly. The heart sounds were normal and the chest was clear. There was marked hypotonia with areflexia. She was drowsy. There were no other abnormal signs in the central nervous system. A soft swelling was palpated over the right upper side of the neck, no bruit or thrill being present. There was no tremor initially and lid-lag and exophthalmos were absent. As she improved with rehydration, she became restless and a fine tremor of the hands appeared.

At this time the haemoglobin was $10.8 \mathrm{~g} /$ $100 \mathrm{ml}$, MCHC $33 \%$, and white cells $19,500 /$ $\mathrm{mm}^{3}$. The blood urea was $288 \mathrm{mg} / 100 \mathrm{ml}$ and plasma electrolytes $(\mathrm{mEq} / 1)$ were: $\mathrm{CO}_{2} \mathrm{CP} 24$, sodium 129, potassium $4 \cdot 1$, chloride 88 and plasma specific gravity $1 \cdot 025$. The serum calcium was $19.0 \mathrm{mg} / 100 \mathrm{ml}$ and the phosphorus $5.9 \mathrm{mg}$ $/ 100 \mathrm{ml}$. The electrocardiogram showed tachycardia but no abnormality of the $Q-T$ or $S-T$ segments or $\mathrm{T}$ wave. A mid-stream specimen of urine contained a trace of protein but no casts or organisms were present.

She was given an intravenous infusion of $0.9 \%$ sodium chloride, dextrose, potassium chloride, hydrocortisone and aramine. With this treatment the blood pressure rose to $130 / 70$. Later on the evening of admission she had a spontaneous abortion, with very little loss of blood.

After the abortion she continued to complain of crampy abdominal pain, and the possibility of pancreatitis was considered and blood was withdrawn for estimation of amylase and lipase (reported after her death as 575 Somogyi units and $4 \cdot 1$ Sigma-Taetz units, respectively).

Although she remained hypotonic, she was restless and had a fine tremor of the hands and feet. At this stage associated thyrotoxicosis was first considered, and the protein-bound iodine and serum cholesterol were estimated (reported after death as greater than $20 \mu \mathrm{g} / 100 \mathrm{ml}$, and $165 \mathrm{mg} /$ $100 \mathrm{ml}$, respectively). X-ray of the hands showed marked subperiosteal erosions, and considerable demineralization.

The following morning the blood pressure was $130 / 80$, the hydration and electrolyte block were normal, the urinary output was $1685 \mathrm{ml}$ over the previous $24 \mathrm{hr}$, and she seemed much better. The blood urea had fallen slightly to $260 \mathrm{mg} / 100 \mathrm{ml}$. In view of the very high serum calcium and improved clinical condition it was decided to carry out an immediate exploration of the parathyroids.

At exploration of the neck, a large adenoma, $\vec{v}$ $4 \mathrm{~cm}$ in diameter, was removed from behind the right lower lobe of the thyroid. The right upper

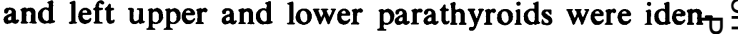
tified and were thought to be normal. A cystio swelling of the right lobe of the thyroid was als $z$ removed.

Post-operatively she continued to have a tachyo cardia of $140 / \mathrm{min}$, and over the next $4 \mathrm{hr}$ it rose to $165-170 / \mathrm{min}$, and at $4 \frac{1}{2} \mathrm{hr}$ it rose to $200 / \mathrm{ming}$ She was transferred to the Cardiac Unit, Roya Victoria Hospital, where she was given intra venous digoxin, neomercazol, intramuscular reserpine and propranolol. She died of a cardiac arrest, attempted resuscitation being unsuccessful.

Shortly before death the serum calcium had fallen to $15.0 \mathrm{mg} / 100 \mathrm{ml}$.

Neropsy (about $8 \mathrm{hr}$ after death). There was extensive fat necrosis of omentum and peritoneum, with focal pancreatitis, nephrocalcinosis, early calcification of the alveolar walls, slight osteitis fibrosa of the vertebrae and ribs, a nodular thyrod with evidence of slight overactivity, pulmonary oedema and early bronchopneumonia. The adenoma removed at operation was composed of sheets of uniform darkly staining cells of chief-cell type, separated into islands by fibrous septa. The other three parathyroids were not hypercellular, and contained the usual fat $D$ content.

\section{Discussion}

Our patient illustrates several problems, namely $\underset{\omega}{N}$ the diagnosis of acute hyperparathyroidism, here masquerading as vomiting of pregnancy; the recognition of thyrotoxicosis in a severely ill 
patient ; the treatment of severe hypercalcaemia.

In the absence of a definite history of stones, bone pains, bone tumour or pathological fracture, the clinical diagnosis of primary hyperparathyroidism requires a high index of suspicion. Vomiting is a feature of acute calcium intoxication, but there are many other causes of vomiting, and when a patient who is pregnant complains of severe vomiting, it may easily be attributed to the pregnancy. Hypotonia is also a feature of acute calcium intoxication, but in a vomiting, very ill patient, the hypotonia may be missed or attributed to accompanying dehydration and hypotension. The presence of conjunctival injection and band keratopathy should, if present, arouse suspicion of hypercalcaemia. Hyperemesis gravidarum is no longer a common condition, and other causes of vomiting should be considered even in pregnancy. Acute hyperparathyroidism occurring in pregnancy has rarely been reported (Petit \& Clarke, 1947; Ludwig, 1962 ; Whalley, 1963) but it may not in fact be rare. The authors have seen one other patient who, while asymptomatic when diagnosed as primary hyperparathyroidism, had suffered from severe vomiting during her recent pregnancy, although vomiting had not been a feature of her two earlier pregnancies (McGeown \& Field, $1960)$. They have also very recently seen another patient (who has not yet undergone surgery) with hypercalcaemia who had marked vomiting during a recent pregnancy although free from vomiting in previous pregnancies. The serum calcium and alkaline phosphatase should be estimated in patients suffering from severe vomiting, and the presence of pregnancy should not be considered a sufficient explanation.

Tachycardia is a feature of acute hyperparathyroidism as well as of thyrotoxicosis. In retrospect, however, a rate of $140 / \mathrm{min}$ may appear too high for calcium intoxication per se. A review of the literature by Lemann \& Donatelli (1964) has shown that in cases of acute hyperparathyroidism while the pulse rate may be as high as 120 , tachycardia is not a constant feature. When hyperparathyroidism co-existed with thyrotoxicosis, tachycardia was always present and ranged from 120 to $160 / \mathrm{min}$ (Bryant, Wulsin \& Altemeirer, 1964). While undue reliance cannot be placed on the presence of tachycardia in very ill dehydrated patients, we suggest that in such patients suffering also from hypercalcaemia, a pulse rate of over $120 / \mathrm{min}$ should suggest the possibility of coexisting thyrotoxicosis.

The co-existence of thyrotoxicosis and acute hyperparathyroidism with pregnancy does not appear to have been reported before. The diagnosis of thyrotoxicosis during pregnancy may be difficult. The thyroid is physiologically hyperactive during pregnancy, so that protein-bound iodine levels and other measures of its function are higher than in the non-pregnant. Radioactive iodine cannot be used freely during pregnancy. Yet, the diagnosis is crucial because surgery may precipitate a thyrotoxic storm, as it appears to have done in our patient. In our patient thyrotoxicosis was suspected because of tachycardia, and the development of a fine tremor and restlessness after her general condition had been improved by rehydration. The result of the protein-bound iodine was not available until after death. Even when recognized, the treatment of thyrotoxicosis presents a problem, as it is unlikely that it could have been brought under control in less than 4 days. In the meantime there was the urgent problem of the very high serum calcium of $19 \cdot 0 \mathrm{mg} / 100 \mathrm{ml}$.

Until very recently, it has been generally accepted that in cases of acute hyperparathyroidism, as soon as the dehydration has been corrected, then an emergency removal of the parathyroid tumour should be carried out. Indeed, we have successfully done this in an unreported case of acute hyperparathyroidism. Recently, however, medical methods of reduction of the serum calcium have been tried.

In 1962 Dent reported that he had treated a severe hypercalcaemic episode in a patient with carcinoma of the parathyroid with first oral, and then intravenous, disodium hydrogen phosphate and obtained a biochemical and clinical remission as far as the hypercalcaemia was concerned. Later the patient developed painful ectopic calcification of fatty tissues and arteries, and he suggested the possibility that the phosphate increased the rate of ectopic calcification. Another patient, in whom repeated parathyroid explorations had failed to reveal a tumour, was treated with oral disodium hydrogen phosphate and her bone lesions healed. In a further report on this patient Dent (1967) reports that after $7 \frac{1}{2}$ years on oral phosphate the osteitis fibrosa returned and she was given calciferol in addition, and after 6 months she developed painful ectopic calcification. He further states that two injections daily of $10 \mathrm{ml}$ of solution of neutral phosphate will usually maintain normocalcaemia indefinitely whatever the cause of the hypercalcaemia, and that he has not encountered any short-term complications. Goldsmith \& Ingbar (1966) reported the use of intravenous phosphate in the treatment of hypercalcaemia of various origins in twenty patients, in all of whom the serum calcium was reduced, usually to normal levels. Unlike our 
patient, most of their patients were not azotaemic and did not already have an elevated phosphate level. The one patient in whom the serum phosphate level was greatly raised died during the infusion, but apparently was already moribund when the infusion was commenced. Ten patients died, and in five of the seven of which there are autopsy details, there was ectopic calcification, but the authors maintain that this need not 'necessarily be ascribed to phosphate administration, since its extent was consistent with the magnitude and duration of pre-existing hypercalcaemia'. Kahil et al. (1967) report the treatment of eleven patients with phosphate, either orally, intravenously or both. The response to oral phosphate was poor but there was a significant reduction of the serum calcium following intravenous phosphate. The autopsy findings in five patients treated with phosphate were compared with those of five hypercalcaemic patients who did not receive phosphate and they did not find more prominent metastatic calcification in the treated patients. Again most of their patients had normal to low serum phosphorus values before the phosphate infusion, and those with already somewhat elevated phosphorus levels all appear to have died. While there is little doubt that intravenous sodium phosphate can usually (but not always-Parsons, Stirling \& Knight, 1967), reduce the serum calcium, of hyperparathyroid origin as well as from other causes, it seems that there is a real risk of the production of ectopic calcification. This risk would presumably be greater in patients with very high levels of serum calcium, especially if the serum phosphorus is already elevated due to renal failure, as it was in our patient. Indeed we would still be reluctant to use it in such circumstances. If we had done so the early calcification of the lungs at autopsy would have worried us. Another danger is the production of hypocalcaemia (Goldsmith \& Ingbar, 1966), but this should be easily correctable if it occurs. However, Shackney \& Hasson (1967) have reported that the rapid fall in serum calcium can be associated with episodes of severe hypotension (even in the absence of hypocalcaemia), and have observed acute renal failure in these circumstances. Acute renal failure may be more likely to occur in kidneys which have recently been subject to hypercalcaemia.

Hypercalcaemia from sarcoidosis, vitamin D intoxication, and some cases of malignant neoplasms, is reduced by steroid therapy. The hypercalcaemia of hyperparathyroidism is usually unaffected by steroids, although it may very rarely be reduced (Gordan, 1960, Dent, 1962).
Steroids are, therefore, not likely to be helpful in the treatment of patients in a parathyroid crisis.

Intravenous infusion of sodium sulphate is known to increase the urinary excretion of calcium (Wolf \& Ball, 1950 ; Walser \& Browder, 1959) but in four patients with hypercalcaemia due to hyperparathyroidism Lemann \& Mehr $\stackrel{\overrightarrow{\mathcal{S}}}{\stackrel{9}{ }}$ (1965) found that intravenous sodium sulphate $\bar{C}$ produced only slight falls in the serum calcium which would not be helpful in treatment, and the serum calcium had increased to the preinfusion value by next morning. Intravenous infusion of saline had a similar effect.

Another possible method of acutely lowering a high serum calcium is the intravenous infusion of sodium ethylene diamine tetra-acetate, but this has been reported as nephrotoxic (Dudley et al., 1955 ; Foreman, Finnegan \& Lushbaugh, 1956), and would, therefore, be unsuitable for use when kidney function is already seriously impaired by nephrocalcinosis.

Calcitonin reduces elevated levels of serum calcium apparently by driving calcium into bone and would, therefore, appear to be the ideato agent for the treatment of hypercalcaemia whicl is dangerous to life. Unfortunately it is not genero ally available, and reports of its use so far hav $\frac{8}{8}$ been disappointing (Foster et al., 1966; Milhaud \& Job, 1966), as the falls produced were smali and transient.

Mithramycin is effective in reducing hypercal caemia due to malignant disease (Parsons, Baurf \& Self, 1967), but its use is as yet restricted by the Dunlop Committee to patients suffering from malignant neoplasms. With personal experience of its effectiveness in reducing the serum calcium from very high levels, and its relative absence of side-effects, even when renal function is impaired, the authors would certainly wish to try it if further patients with very high levels of serum calcium due to hyperparathyroidism are encountered. It was not available at the beginning of 1966, when this patient was seen.

Haemodialysis against a dialysate low in calcium ought to be eminently suitable for lowering the serum calcium in hypercalcaemia, without risk of production of ectopic calcification or other side effects. Bacon, Ware \& Loomis (1966) have demonstrated an average loss of about $7 \mathrm{~g}$ calcium per dialysis when the calcium content of the dialysate is below $5 \mathrm{mg} / 100 \mathrm{ml}$. We have found that using Kiil dialysers, up to $6 \mathrm{~g}$ calcium can be removed over $14 \mathrm{hr}$ when the concentration of calcium in the dialysate is $2-3 \mathrm{mg} / 100 \mathrm{ml}$ (unpublished observations). When the serum calcium is very high a much greater loss could be expected. Using a Kiil dialyser the possibility of 
hypotension from a too sudden fall in the serum calcium should be minimized, and uraemia, if present would also be benefitted. However, Davidson \& Pendras (1967) were unsuccessful in attempts to lower the serum calcium by haemodialysis against a calcium-free dialysate in two patients with chronic renal failure who were hypercalcaemic from secondary hyperparathyroidism and vitamin $\mathrm{D}$ treatment. Both patients died. Nielsen (1967) has very recently reported that haemodialysis reduced the serum calcium from very high levels in a patient similar to ours. We did consider this method of treatment for our patient, but we felt that the improvement in clinical condition and good urinary output following rehydration justified the immediate attempt to remove the parathyroid adenoma, as a more certain method of reducing the serum calcium. In retrospect we believe that dialysis against a low calcium dialysate might have been beneficial, and would use this method if in a similar dilemma.

The patient also had clinical, biochemical and finally autopsy evidence of pancreatitis. This relatively rare, but very serious, complication of hyperparathyroidism occurs most often in patients in whom the serum calcium level is very high, and is another reason for the urgent necessity to reduce the serum calcium as sometimes rapid improvement follows removal of the adenoma (Cope et al., 1957).

Conflicting observations on the effect of pregnancy on hyperparathyroidism have been reported. It has been claimed on the basis of animal experiments in which acute hyperparathyroidism was induced by parathormone, that the pregnant animal is protected (Lehr \& Krukowski, 1961). Furthermore there are a number of reported instances when neonatal tetany led to the diagnosis of hyperparathyroidism in the mother (Freiderichsen, 1939; Talbot et al., 1952 ; Walton, 1954 ; Van Arsdel, 1955; Bruce \& Strong, 1955; McGeown \& Field, 1960 ; Hutchin \& Kessner, 1964 ; Hartenstein \& Gardner, 1966), so that the disease must have been relatively benign during pregnancy. Others hold the view that pregnancy worsens the course of hyperparathyroidism. Albright \& Reifenstein (1948) mention that pregnancy is associated with hyperplasia of the parathyroid glands and attribute the greater prevalence of hyperparathyroidism amongst females to this. Petit \& Clarke (1947) report a 23-year-old patient who presented during pregnancy with a mass in the mandibular region which had recently enlarged, and who had a serum calcium of $19.0 \mathrm{mg}$ $/ 100 \mathrm{ml}$. The mass was a $13 \mathrm{~g}$ parathyroid adenoma. Others have reported an increased prevalence of miscarriages, stillbirths and prematurity in hyperparathyroid mothers (Walton, 1954; Ludwig, 1962; Wagner, Transbol \& Melchior, 1964). Whalley (1963) found nephrocalcinosis in the foetus in one of her four cases. The calcium drain by the foetus may provoke further hyperactivity of the parathyroid, thus accelerating the evolution of the disease. In three (including our case) of the twenty-four reported instances of the association of hyperparathyroidism and pregnancy the patients had acute symptoms. In the patients in whom the diagnosis was made during pregnancy the average serum calcium was high $(15.3 \mathrm{mg} / 100 \mathrm{ml})$ suggesting a severe type of the disease.

It is well recognized that hypercalcaemia occurs in some patients with thyrotoxicosis. When thyrotoxicosis co-exists with hyperparathyroidism it might be expected to potentiate the hypercalcaemia. Hamilton et al. (1936) have shown that exogenous parathyroid hormone produces a greater elevation of the serum calcium in patients with thyrotoxicosis than in euthyroid subjects.

In our patient, both pregnancy and thyrotoxicosis may have accelerated the evolution of acute calcium intoxication. Death was due to a thyrotoxic storm following surgery. Tachycardia in patients with hypercalcaemia, especially if above $120 / \mathrm{min}$, should suggest the possibility of thyrotoxicosis as well as hyperparathyroidism. In such cases the hypercalcaemia should be treated medically, by one of the methods described, and surgery should be delayed, if at all possible, until the thyrotoxicosis is controlled. Acute pancreatitis was also present.

The possibility of hypercalcaemia should be considered in all cases of hyperemesis gravidarum.

\section{References}

Albright, F. \& Reifenstein, E.C. (1948) Parathyroid Glands and Metabolic Bone Disease. Williams \& Wilkins, Baltimore.

AUSTONI, M. (1965) Acute thyro-parathyrotoxicosis. Postgrad. med. J. 41, 252.

BACON, D., WARE, F. \& Loomis, G. (1966) Calcium and phosphorus changes during chronic haemodialysis. Clin. Res. 14, 446.

BrUCE, J. \& Strong, J.A. (1965) Maternal hyperparathyroidism and parathyroid deficiency in the child. Quart. J. Med. 24, 307.

Bryant, L.R., Wulsin, J.H. \& Altemeirer, W.A. (1964) Hyperparathyroidism and hyperthyroidism. Ann. Surg. $159,411$.

Cope, O., Culver, P.J., Mixter, C.G. \& Nardi, G.L. (1957) Pancreatitis, a diagnostic clue to hyperparathyroidism. Ann. Surg. 145, 857. 
Davidson, R.C. \& Pendras, J.P. (1967) Calcium-related cardio-respiratory death in chronic hemodialysis. Trans. Amer. Soc. art. int. Org. 13, 36.

DENT, C.E. (1962) Some problems of hyperparathyroidism. Brit. med. J. ii, 1495.

DENT, C.E. (1967) Emergency treatment of hypercalcaemia. Lancet, ii, 613.

Dudley, H.R., Ritchie, A.C., Schilling, A. \& BaKer, W.H. (1955) Pathologic changes associated with the use of sodium ethylene diamine tetra-acetate in the treatment of hypercalcaemia. New Engl. J. Med. 252, 331.

Foreman, H., Finnegan, C. \& Lushbaugh, C.C. (1956) Nephrotoxic hazard from uncontrolled edathamil Ca-Na therapy. J. Amer. med. Ass. 160, 1042.

Foster, G.V., Joplin, G.F., Macintyre, I. \& Melvin, K.E.W. (1966) Effect of thyrocalcitonin in man. Lancet, $\mathbf{i}$, 107.

Friderichsen, C. (1939) Tetany in a suckling with latent osteitis fibrosa in the mother. Lancet, $\mathbf{i}, 85$.

GolDSMITH, R.S. \& INGBAR, S.H. (1966) Inorganic phosphate treatment of hypercalcaemia of diverse origins. New Engl. J. Med. 274, 1.

GordaN, G.S. (1960) Current status of laboratory tests for hyperparathyroidism. Acta endocr. (Kbh.) 35, Suppl. 51, 463.

Hamilton, B., De Sef, L., Highman, W.J., JR \& Schwartz, C. (1936) Parathyroid hormone in the blood of pregnant women. J. clin. Invest. 15, 323.

HARTENSTEIN, H. \& GaRdNER, L.I. (1966) Tetany of the new born associated with maternal parathyroid adenoma. New Engl. J. Med. 274, 266.

Hutchin, P. \& KESSNER, D.M. (1964) Neonatal tetany: diagnostic clue to hyperparathyroidism in the mother. Ann. intern. Med. 61, 1109.

Kahil, M., Orman, B., Gyorkey, F. \& Brown, H. (1967) Experience with phosphate and sulphate therapy. J. Amer. med. Ass. 201, 721.

LEHR, D. \& KRUKOWSKI, M. (1961) Protection by pregnancy against the sequelae of acute hyperparathyroidism. Naunyn-Schmiedeberg's Arch. exp. Path. Pharmak 242, 143.

LemanN, J. \& Mehr, M.P. (1965) Sodium sulphate infusions and hypercalcaemia. J. Amer. med. Ass. 194, 1126.
Lemann, J. \& Donatelli, A.A. (1964) Calcium intoxication due to primary hyperparathyroidism. Ann. intern. Med. 60, 447.

LUDWIG, G.D. (1962) Hyperparathyroidism in relation to pregnancy. A medical and surgical emergency. New Engl. J. Med. 267, 637.

Milhaud, G. \& JoB, J.C. (1966) Thyrocalcitonin: effect on iodiopathic hypercalcaemia. Science, 154, 794.

McGeown, M.G. \& Field, C.M.B. (1960) Asymptomatic hyperparathyroidism. Lancet, ii, 1268.

NielseN, B. (1967) Emergency treatment of hypercalcaemia. Lancet, ii, 1090.

Parson, V., Baum, M. \& Self, M. (1967) Effect of Mithramycin on calcium and hydroxyproline metabolism in patients with malignant disease. Brit. med. J. i, 474

Parsons, V., Stirling, G. \& Knight, E. (1967) Fatal hypercalcaemia complicating carcinoma of breast, resistant to cortisone and phosphate administration. Brit. med. J. iv, 658.

Petit, D.W. \& Clark, R.L. (1947) Hyperparathyroidism and pregnancy. Amer. J. Surg. 74, 860.

ShaCkNey, S. \& Hasson, J. (1967) Precipitous fall in serum calcium, hypotension and acute renal failure after intravenous phosphate therapy for hypercalcaemia. Ann. inter. Med. 66, 906.

Talbot, N.B., Sobel, E.H., McArthur, J.W. \& CraWford, J.D. (1952) Functional Endocrinology from Birth through Adolescence, p. 118. Howard University Press, Cambridge, Massachusetts.

VAN ARSDEL, P.P. (1965) Maternal hyperparathyroidism asp a cause of neonatal tetany. J. clin. Endocr. 15, 680.

Wagner, G., Transbol, I. \& Melchior, J.C. (1964) Hypeic parathyroidism and pregnancy. Acta endroc. (Kbh.) 47 549.

WAlser, M. \& Browder, A.A. (1959) The effect of sulphat infusion on calcium excretion. J. clin. Invest. 38, 1404.

Walton, R.L. (1954) Neonatal tetany in two siblings: effect of maternal hyperparathyroidism. Pediatrics, 13, 227.

Whalley, P.J. (1963) Hyperparathyroidism and pregnancy Amer. J. Obstet. Gynec. 86, 517.

WolF, A.V. \& BaLl, S.M. (1950) Effect of intravenous sodium sulfate on renal excretion in dog. Amer. J. Physiol. $160,353$. 